\title{
Canonical Correlation Analysis of Leisure Behavior and Satisfaction of Hearing Impaired College Students in Leisure Industry
}

\author{
Xin Wei ${ }^{1}$, Ye Yang ${ }^{2}$, JuFen Yu, ${ }^{1, *}$ \\ ${ }^{1}$ School of special education, Leshan normal university, Leshan Sichuan, China \\ ${ }^{2}$ Wenzhou Xiexin Education Information Consulting Co., Ltd., Wenzhou Zhejiang, China \\ *Corresponding author
}

\begin{abstract}
With the transformation of various industries, a series of changes have taken place in the leisure industry. The college students with hearing impairment are a special group, and the quality of leisure life plays a decisive part of their physical and psychological development.In order to understand the relationship between leisure behavior and leisure satisfaction of hearing-impaired college students, 77 hearing-impaired college students from Leshan normal university were sampled by cluster to conduct a questionnaire survey. The results showed that the leisure behavior and leisure satisfaction of the hearing-impaired students were at medium level. Except for the correlation between recreation and health satisfaction, which is not remarkable, there is a significantly positive correlation between each dimension of leisure behavior and leisure satisfaction. The canonical correlation analysis showed that the influence of leisure behavior on leisure satisfaction was greater than that of leisure satisfaction on leisure behavior. Community organization and recreation in leisure behavior had positive effects on cognitive satisfaction.
\end{abstract}

Key words: hearing-impaired college students, leisure behavior, leisure satisfaction, canonical correlation analysis, leisure industry

\section{Problem posing}

The critical time for talents development occurs at the university. Leisure life is considered as an indispensable part of college students' life, during which college students can enjoy abundant spare time, and the quality of leisure life will not only directly influence their cognitive and experience ability but affect personal future development [1].

Leisure behavior is a process in which individuals can spontaneously select and participate in activities which are helpful for physical rest at free time. College students' leisure behavior includes all ranges of activities- excluding finishing schoolwork and psychologically-meeting types- for instance, academic extension activities, school community activities, recreation, sports, social activities etc. Leisure behavior usually is associated with personal sense of joy, happiness and harmony with others. Research suggests that higher degree of college students' involvement with social, sports and recreational activities leads to higher satisfaction of their social identification [2]. While Chinese college students mainly enjoy recreational activities [3], rather than sports activities. It seems that there is bias in their values of leisure [4]. Therefore, proper and appropriate leisure education of college students will play a crucial role in experiencing high-quality campus life, promoting their physical and psychological health and gaining higher sense of happiness.

With the continuous progression of the higher education for people with disability in China, an increasing number of students with hearing impairment are admitted into universities. They also face academic pressure like other ordinary college students, and their leisure life may be affected by poor communications. According to some surveys, there is a positive tendency to recreational attitude among students with hearing impairment [5]. Communicating online is a common way for this group of students [6], while some researches also suggest that, leisure activities will have a remarkable impact on leisure satisfaction among hearing impaired college students, whereas personal leisure activities do not have significant effects on leisure satisfaction [7]. College years is a

ISSN: 0010-8189

(C) CONVERTER 2020

www.converter-magazine.info 
critical period for hearing-impaired college students to develop their philosophy and value, and the quality of leisure life plays a decisive part of their physical and psychological development and gaining greater happiness and sense of belonging on campus life. Thus, this study intends to take the hearing-impaired college students as subjects to survey their leisure behavior performance and the relation with leisure satisfaction, so as to further explore the influence between the two.

\section{Research methods}

\subsection{Research Objects}

The research applied cluster sampling, surveying 77 college students with hearing impairment from Leshan Normal University. 74 questionnaires were reclaimed and the effective rate was $96.1 \%$. There were 31 male students and 43 female students in the surveyed group.

\subsection{Research Tools}

\subsubsection{Leisure Behavior Questionnaire}

Questionnaire on college students' leisure behavior written by Gao Qiang [8] was applied, and tallied 28 items, which involve 5 dimensions: community organizations, entertainment and recreation, social activities, academic extension and limb movement. Respectively, community organizations refers to activities organized by students after finishing schoolwork; entertainment and recreation are personal interests which can relieve oneself psychologically and physically; social activities refer to all kinds of programme that hold individual social interaction and compose of personal social relationships; academic extension refers to leisure activities associated with improving professional abilities; and limb movements are some leisure projects relating to physical power and movement skills. Bases on 3 points score, from 1"never" to 3 "frequent", the total score is 84 scores. Higher scores indicate higher leisure behavior participation. Cronbach's $\alpha$ of this measurement is 0.86 .

\subsubsection{Leisure Satisfaction Questionnaire}

The research applied questionnaire on leisure satisfaction of college students written by Liu Qingliang [9], with a total of 18 items, containing 5 dimensions: health satisfaction, cognitive satisfaction, emotional satisfaction, group relationship satisfaction and personal value satisfaction. Health satisfaction signifies satisfaction with pressure relief both physically and psychologically; cognitive satisfaction refers to satisfaction with knowledge, experience and other aspects; emotional satisfaction means keeping mind steady and feeling satisfied with returning to self and nature; group relationship is relating to interpersonal relation satisfaction which includes families, friends and other relations; and personal value means the satisfaction with individual potential cultivation and sense of value. The questionnaire uses 4 points to score, from 1"acquire none" to 4“acquire much", with a total of 76 scores.

\subsection{Measured}

The main survey was conducted by professional special education faculty, and they used sign language to ask the hearing impaired college students to complete the questionnaires and reclaimed them immediately on the spot.

\subsection{Data Processing}

Data were input to SPSS22.0 data statistic software which was used to analyze and process, and the descriptive statistical analysis, Pearson correlation analysis, canonical correlation analysis were used in this research.

\section{Results}

3.1 The overall state of leisure behavior and leisure satisfaction of college students with hearing impairment

According to table 1, the overall participation in leisure behavior of college students with hearing impairment is at middle level. Rankings based on the average scores from high to low respectively are community organizations, 
entertainment and recreation, social activities, academic extension and limb movement. The former two hit the top and the mean values are relatively close.

Leisure satisfaction of hearing- impaired college students reaches middle level. From the result of the average scores, the group relationship satisfaction was the highest, followed by cognitive satisfaction, health satisfaction, personal value satisfaction, and emotion satisfaction was left at the bottom.

Table 1 Leisure behavior and leisure satisfaction of college students with hearing impairment

\begin{tabular}{cccccc}
\hline Leisure behavior & $\mathrm{M}$ & SD & Leisure satisfaction & $\mathrm{M}$ & SD \\
\hline $\begin{array}{c}\text { Community } \\
\text { organizations }\end{array}$ & 2.05 & 0.45 & Health satisfaction & 2.54 & 0.58 \\
Entertainment & 2.04 & 0.44 & Cognitive satisfaction & 2.58 & 0.64 \\
Social activities & 1.77 & 0.35 & Emotion satisfaction & 2.37 & 0.74 \\
Academic extension & 1.68 & 0.35 & Group relationship & 2.65 & 0.67 \\
Limb movement & 1.62 & 0.32 & Personal value satisfaction & 2.42 & 0.71 \\
Total & 1.77 & 0.28 & Total & 2.52 & 0.55 \\
\hline
\end{tabular}

3.2 Simple correlation of leisure behavior and leisure satisfaction of college students with hearing impairment

Pearson correlation was applied to analyze the leisure behavior and leisure satisfaction of college students with hearing impairment. The result in table 2 shows that except for the correlation between leisure behavior and health satisfaction, which is not remarkable $(\mathrm{P}>0.05)$, there is a significantly positive correlation between each dimension of leisure behavior and leisure satisfaction. $(\mathrm{P}<0.05, \mathrm{P}<0.01)$.

Table 2 Correlation analysis on leisure behavior and leisure satisfaction of college students with hearing impairment

\begin{tabular}{|c|c|c|c|c|c|}
\hline Items & $\begin{array}{l}\text { Community } \\
\text { organizations }\end{array}$ & $\begin{array}{l}\text { Entertainm } \\
\text { ent }\end{array}$ & $\begin{array}{r}\text { Social } \\
\text { activities }\end{array}$ & $\begin{array}{l}\text { Academic } \\
\text { extension }\end{array}$ & $\begin{array}{c}\text { Limb } \\
\text { movement }\end{array}$ \\
\hline $\begin{array}{l}\text { Health } \\
\text { satisfaction }\end{array}$ & $0.36^{* *}$ & 0.19 & $0.31^{* *}$ & $0.32^{* *}$ & $0.30^{\text {** }}$ \\
\hline $\begin{array}{l}\text { Cognitive } \\
\text { satisfaction }\end{array}$ & $0.45^{* * *}$ & $0.44^{* *}$ & $0.34^{* *}$ & $0.36^{* *}$ & $0.33^{* *}$ \\
\hline $\begin{array}{l}\text { Emotion } \\
\text { satisfaction }\end{array}$ & $0.38^{* * *}$ & $0.27^{*}$ & $0.28^{* *}$ & $0.23^{* *}$ & $0.29^{* * *}$ \\
\hline $\begin{array}{l}\text { Group } \\
\text { relationship } \\
\text { satisfaction }\end{array}$ & $0.47^{* *}$ & $0.25^{*}$ & $0.35^{\text {*** }}$ & $0.49^{* *}$ & $0.45^{* * *}$ \\
\hline $\begin{array}{l}\text { Personal value } \\
\text { satisfaction }\end{array}$ & $0.39^{* *}$ & $0.29^{*}$ & $0.37^{* *}$ & $0.30^{* *}$ & $0.47^{* *}$ \\
\hline
\end{tabular}

Note: $* \mathrm{P}<0.05, * * \mathrm{P}<0.01$

3.3 Canonical correlation analysis on leisure behavior and leisure satisfaction of college students with hearing impairment

Because simple correlation analysis discussed the correlation between dimensions of both variables but failed to reveal the overall correlation between leisure behavior and leisure satisfaction. Because of this, Canonical correlation analysis was applied to deeply investigate the overall relevance between leisure behavior and leisure satisfaction. According to the result, among the canonical correlation analysis, only one pair of canonical correlation variables reach the statistical level, and its coefficient is $0.61(\mathrm{P}<0.01)$, therefore, the research conducted analysis on canonical variable correlation, and more details are showed in table 3. Leisure behavior can explain $52.5 \%$ variation by its own canonical variables, while leisure satisfaction can explain $55.9 \%$ variation by

ISSN: 0010-8189 
its own canonical variables. Among the factors affecting the leisure behavior, $19.6 \%$ can be explained by leisure satisfaction; and among the elements affecting leisure satisfaction, $20.9 \%$ of them can be explained by leisure behavior. The square of the canonical correlation coefficient of the two groups of variables is 0.372 , so the shared variance is $37.2 \%$. And in terms of the shared variance and overlapping index, leisure behavior and satisfaction are moderately low correlated, which is in accordance with the result in simple correlation analysis.

Table 3 suggests that there are higher canonical coefficients and canonical loadings for occupational entertainment and recreation in leisure behavior; and cognitive satisfaction which affiliates to leisure satisfaction also gets higher canonical coefficient and canonical loadings than other dimensions. Therefore, it can be considered that the association among community organization, recreation and cognitive satisfaction is more closely related.

Table 3 Canonical correlation analysis on leisure behavior and leisure satisfaction of college students with hearing

\begin{tabular}{|c|c|c|c|c|c|}
\hline Leisure behavior & $\begin{array}{l}\text { Canonical } \\
\text { coefficients }\end{array}$ & $\begin{array}{l}\text { Canonical } \\
\text { loadings }\end{array}$ & $\begin{array}{l}\text { Leisure } \\
\text { satisfaction }\end{array}$ & $\begin{array}{l}\text { Canonical } \\
\text { coefficients }\end{array}$ & $\begin{array}{l}\text { Canonical } \\
\text { loadings }\end{array}$ \\
\hline $\begin{array}{l}\text { Community } \\
\text { organizations }\end{array}$ & -0.44 & -0.83 & $\begin{array}{l}\text { Health } \\
\text { satisfaction }\end{array}$ & 0.35 & -0.61 \\
\hline Entertainment & -0.49 & -0.75 & $\begin{array}{l}\text { Cognitive } \\
\text { satisfaction }\end{array}$ & -0.76 & -0.90 \\
\hline Social activities & -0.17 & -0.65 & $\begin{array}{l}\text { Emotion } \\
\text { satisfaction }\end{array}$ & -0.09 & -0.65 \\
\hline $\begin{array}{l}\text { Academic } \\
\text { extension }\end{array}$ & -0.09 & -0.64 & $\begin{array}{l}\text { Group } \\
\text { relationship } \\
\text { satisfaction }\end{array}$ & -0.27 & -0.79 \\
\hline Limb movement & -0.14 & -0.74 & $\begin{array}{l}\text { Personal value } \\
\text { satisfaction }\end{array}$ & -0.35 & -0.76 \\
\hline $\begin{array}{l}\text { Self-correlated } \\
\text { coefficient }\end{array}$ & $52.5 \%$ & & & $55.9 \%$ & \\
\hline $\begin{array}{l}\text { Overlapping } \\
\text { index }\end{array}$ & $19.6 \%$ & & & $20.9 \%$ & \\
\hline
\end{tabular}

\section{Discussion}

\subsection{Analysis on leisure behavior performance of college students with hearing impairment}

On the whole, leisure behavior of hearing-impaired college students shows a medium level. The mean values of each dimension imply that participation of community organizations is the highest, which on the one hand, is related to the active guidance of colleges and universities. Usually, universities and colleges encourage students to join in students' union, clubs and some other organizations to enrich their after- school life and facilitate personal qualities; on the other hand, due to their particularities, hearing-impaired students' behavior usually tend to be group- compliant, thus, clubs and organizations which they are interested in can provide group supporting for them to some extent, and also offer them far more possibilities to contact with the outside world. The results of the research find that score in mean value of entertainment and recreation is higher as well, at the same time, it is close to the score in community organizations, which is consistent with the result of recorded research of ordinary college students [10][11] that browsing the internet, chatting and hanging out still are the mainstream leisure activities for hearing-impaired college students, while the participation of activities with academic extension and limb movement are low. Based on the Hierarchical Model of Leisure devised by American scholar Nash, college students with hearing impairment mainly join in activities that can get rid of monotony and kill time, while the performance of activities ranked creativeness is low. This may also be related to hearing limitation and forms of communication barriers, hence, there is a priority for activities with general leisure requirement or that is far more familiar with. Nevertheless, what is worthy of attention is that the engagement of physical activities of hearing impaired college students is the same as that of ordinary college students, and the overall participation is far from optimistic. Studies show that workout and recreational activities are beneficial to physical and psychological health, so for the hearing-impaired college students, sports and leisure education is also an area that needs greater ISSN: 0010-8189 
attention.

\subsection{Analysis on leisure satisfaction of hearing-impaired college students}

The research result implies that hearing-impaired college students are basically content with their leisure life which is in accordance with the existed researches [5]. Among 5 dimensions of leisure satisfaction, the group relationship satisfaction is highest, indicating that hearing-impaired college students attach more importance to the positive effects on interpersonal relations brought from the entertainment. Some studies have pointed out that most hearing-impaired students are willing to interact with ordinary people [6], while they usually attend special schools and live in limited social circles before entering colleges. College life offers them broader horizon and communication groups and this serves as an explanation for higher group relationship satisfaction. In addition, scores in cognitive satisfaction and health satisfaction also rank higher than other aspects, showing that hearingimpaired college students also concern about knowledge and experience growth and physical and mental health benefits brought by leisure activities.

\subsection{Correlation analyses on leisure behavior and leisure satisfaction of hearing-impaired college students}

As the research implemented the simple correlation analyses on leisure behavior and leisure satisfaction, it has been found that except for the insignificant correlation between leisure and health satisfaction, the other dimensions reach significant positive correlation between each dimension, which indicates that, generally, higher participation in leisure activities lead to higher leisure satisfaction of hearing-impaired college students, and this in accordance with the recorded conclusion of the research [7]. Thus, it can be considered that regardless of individual or group, static or dynamic, recreational or developmental leisure activities, as long as they actively participate in them, the hearing-impaired college learners can get pleasant experience in cognition, emotion and values. And higher leisure satisfaction will prompt hearing-impaired college students to participate in all ranges of leisure activities. While the correlation relevance between recreational activities and health satisfaction are far from remarkable, and this demonstrates that hearing-impaired college students feel that recreational activities such as playing cards and computer games is not beneficial to their health.

The research conducted canonical correlation analyses for further exploration on the relationship between leisure behavior and leisure satisfaction. Canonical correlation analysis is applied to analyze two sets of variables as a whole variable, and that can reflect their relationship in a better way, meanwhile, the canonical variables can be found from the observed variables, which can reflect the cause of the variation to a full extent, serving as a more appropriate explanation for the result. According to the result in this research, the relation between the leisure behavior and leisure satisfaction is revealed in the first pair of canonical variables. The result proves that the former explains $21.1 \%$ of leisure satisfaction, while the latter accounts for $19.8 \%$ of the former. Accordingly, it is considered that the effect of leisure behavior on leisure satisfaction is greater than that of leisure satisfaction on leisure behavior. Based on canonical coefficient and canonical loadings of the two dimensions, community organizations and recreational activities have greater impact on cognitive satisfaction. In other words, higher participation in community organizations and recreational activities contributes to higher personal cognitive satisfaction. Thus, it is considered that by joining in students organizations and community activities, hearingimpaired college students can expand personal cognitive experience in various social circles; they can explore more interests from group activities, and these activities even influence their life attitude and occupational orientation [6]. Lower though the rank of recreational activities is, for hearing-impaired college students, they can feel freer and more comfortable, especially because the Internet era comes forward, allows them to acquire more knowledge via media, such as computers and mobile phones, thus, students properly avoid communication barriers resulting from hearing impairment. Furthermore, it is an indication that providing more diverse student organization activities, rationally guiding and holding leisure activities for those college students with hearing impairment will help broaden their knowledge and experience, and promote their sense of satisfaction, happiness and belonging in higher education. 


\section{Conclusion}

(1) Leisure behavior and leisure satisfaction of college students with hearing impairment is generally at medium level.

(2) Except for the correlation between recreation and health satisfaction, which is not remarkable, there is a significantly positive correlation between each dimension of leisure behavior and leisure satisfaction.

(3) The effect of leisure behavior of hearing- impaired college students on leisure satisfaction is greater than that of leisure satisfaction on leisure behavior, and the community organizations and recreational activities in leisure behavior play positive roles in promoting cognitive satisfaction.

\section{References}

[1] DeMing Cui, YingHua Deng, "Research on the leisure behavior of college students -- a case study of college students in Changsha," Forum on Contemporary Education, no. 4, pp. 69-72, 2011.

[2] ZhengHan $\mathrm{Pu}$, Jialin XU, "The relationship between leisure participation," leisure restriction and leisure satisfaction of college students.Contemporary Sports Technology, vol. 5, no. 26, pp.152-154, 2015.

[3] XiaoPing Liao, Huan Sun, "College students' leisure education.Modern University Education,” no. 1, pp. 95-100, 2011.

[4] XuePing Mai, "Sports leisure behaviors and leisure value orientations of college students in Guangdong province," Journal of Physical Education, vol. 20, no. 2, pp. 73-75, 2013.

[5] FuJia Tang, "Research on the leisure behavior characteristics of hearing-impaired college students," Journal of Hebei Tourism Vocational College, vol. 21, no. 2, pp. 55-61, 2016.

[6] WenLi Chen, "Research on the Recreational and Leisure Activities of the Young Hearing-impaired Group in the Internet Age,” Tourism Tribune, vol. 27, no. 7, pp. 91-97, 2012.

[7] FuJia Tang, XiaoYan Chen, "The relationship between leisure motivation, leisure participation and satisfaction of hearing-impaired college students," Journal of Nanjing Xiaozhuang University, vol. no. 5, pp. 100-105, 201.

[8] Qiang Gao, "Relationship between College students' leisure behavior and leisure satisfaction," China: Southwest university, 2009.

[9] QingLiang Liu, ChaoHui Zhang, "SEM-based Analysis on Relationship between Sport Leisure Satisfaction and Motivation of College Students," China Sport Science, vol. 29, no. 4, pp. 80-83, 2009.

[10] XiaoHua Zeng, "Analysis of the daily behaviors of contemporary college students," Modern Economic Information, no. 5, pp. 421-436, 2015.

[11] HongXie Shi, "Leisure education for college students and spiritual adults," China Youth Study, no. 3, pp.75-78, 2005. 